\title{
CLINICAL PROFILE OF FALCIPARUM MALARIA WITH SPECIAL REFERENCE TO ACUTE KIDNEY INJURY- A HOSPITAL-BASED OBSERVATIONAL STUDY
}

\author{
Bhaskar Baruah', Subhajit Mitra², Diganta Buragohain ${ }^{3}$ \\ ${ }^{1}$ Associate Professor, Department of Medicine, Gauhati Medical College and Hospital, Guwahati, Assam, India. \\ ${ }^{2}$ Registrar, Department of Medicine, Gauhati Medical College and Hospital, Guwahati, Assam, India. \\ ${ }_{3}^{3}$ Postgraduate Trainee, Department of Medicine, Gauhati Medical College and Hospital, Guwahati, Assam, India.
}

\section{ABSTRACT}

\section{BACKGROUND}

Malaria is very frequent in our state and acute kidney injury is a frequent complication. The objectives of this study were to evaluate the clinical features of falciparum malaria and its impact on kidney functions and the short-term outcomes.

\section{MATERIALS AND METHODS}

This was a hospital-based observational study, where 120 falciparum cases were studied in detail in a period of one year. A detailed history, thorough clinical examination and relevant investigations were done in patients suffering from falciparum malaria. AKIN criteria were used to define acute kidney injury.

\section{RESULTS}

Fever was the most common clinical feature which was present in $100 \%$ of the patients and associated chills and rigors were seen in $95.8 \%$ cases. $70.83 \%$ cases were complicated (severe) falciparum malaria and rest of $29.16 \%$ cases were uncomplicated. Acute kidney injury was seen in $34.16 \%$ patients. About $46.4 \%$ patients were in stage 3 AKIN. $60.9 \%$ cases required haemodialysis. There was $13.33 \%$ mortality in our study due to falciparum malaria. Malarial AKI attributed to $24.39 \%$ of the mortality.

\section{CONCLUSION}

Among the complicated cases, most of the patients had malarial acute kidney injury and required haemodialysis. Majority of the AKI patients presented with oliguria and albuminuria. Mortality was higher in patients with acute kidney injury.

\section{KEY WORDS}

Falciparum Malaria, Acute Kidney Injury, AKIN Staging, Haemodialysis.

HOW TO CITE THIS ARTICLE: Baruah B, Mitra S, Buragohain D. Clinical profile of falciparum malaria with special reference to acute kidney injury- a hospital-based observational study. J. Evolution Med. Dent. Sci. 2018;7(24):2851-2854, DOI: $10.14260 /$ jemds/2018/643

\section{BACKGROUND}

Malaria is the most important parasitic disease of the humans and most common cause of fever in tropical countries. Human malaria can be caused by all species of Plasmodium, but falciparum malaria has greatest clinical importance because of its life-threatening complications. Mortality rate is $6.4 \%$ when one or few organs fail, but increases to $48.8 \%$ with multiorgan failures. ${ }^{1}$ The development of these complicated forms of falciparum malaria and also the mortality depend upon the immune status and virulence of the falciparum strain. Kidneys are one of the most commonly involved organs in falciparum malaria. In 1944, Spitz observed acute renal failure due to falciparum infection in soldiers during World War II. Acute kidney injury (AKI) is one of the most dreaded complications of severe falciparum malaria. ${ }^{2}$ The overall prevalence of AKI in falciparum malaria varies between $<1$ and $60 \%$ with the mortality rate up to $45 \% .^{2,3}$

'Financial or Other Competing Interest': None.

Submission 23-04-2018, Peer Review 27-05-2018,

Acceptance 02-06-2018, Published 11-06-2018.

Corresponding Author:

Subhajit Mitra,

Department of Medicine,

Gauhati Medical College and Hospital,

Guwahati,

Assam, India.

E-mail: subhajitrocks@gmail.com

DOI: $10.14260 /$ jemds $/ 2018 / 643$

\section{(c) $(\mathbf{5})$}

Mild proteinuria to severe azotaemia with metabolic acidosis are the usual renal complications. It may be oliguric or non-oliguric. AKI may be present as a component of multiorgan dysfunction or as a lone complication in which the prognosis is better. The clinical manifestation is attributed to diverse pathogenic interplay. Acute tubular necrosis and mild proliferative glomerulonephropathy are the major histologic changes. Progression to chronic kidney disease is rare. ${ }^{2}$ Assam contributes more than $5 \%$ of total malaria cases in the country annually. Plasmodium falciparum accounts for 58$68 \%$ of the cases and the remainder are due to $P$. vivax. Malaria is spreading to new areas, where there is enhanced morbidity and mortality. 122 primary health centres in Assam are identified as being high risk for malaria based on the selected epidemiologic criteria and nearly $65 \%$ of the total population of the state ( 26.6 million) is estimated to be living in high-risk areas. The number of malaria deaths in Assam in 2012 was 13, which came down to 7 in 2013 and 11 in 2014.4 Gauhati Medical College and Hospital renders services to the population of Assam and the neighbouring few districts of Arunachal Pradesh, Nagaland and Manipur and Meghalaya. Therefore, the study titled "Clinical profile of falciparum malaria with special reference to acute kidney injury" was undertaken on clinical presentations, complications and renal profile among the confirmed cases of falciparum malaria with the following aims and objectives-

- To study the clinical features of falciparum malaria.

- To study its impact on kidney functions.

- To study the short-term outcome. 


\section{MATERIALS AND METHODS}

\section{Study Area}

This study was conducted at Gauhati Medical College and Hospital, Guwahati, Assam. 120 adult patients of smear positive falciparum malaria with various complications were admitted to Department of Medicine and Nephrology.

\section{Study Design}

This was a hospital-based observational study from $1^{\text {st }}$ June 2014 to $30^{\text {th }}$ May 2015. Informed consent was obtained. Ethical committee clearance was taken. Data which included demographic profile, clinical features, investigations, treatment and complication from all indoor patients were collected and analysed. WHO criteria for severe falciparum malaria was used. 5 AKIN criteria was used for acute kidney injury. 6

\section{Inclusion Criteria}

All positive for falciparum malaria (either by peripheral smear or rapid diagnostic test) and above 12 years were included.

\section{Exclusion Criteria}

Acute kidney injury due to other diseases like infectious diarrhoea, dengue fever, typhoid, leptospirosis, patients with pre-existing renal diseases patients on nephrotoxic drugs were excluded from the study.

\section{Method of Data Collection}

1. Interviewing patients and attendants.

2. By thorough physical examination.

3. Relevant investigations.

Data were recorded into a preformed and pretexted proforma. Statistical analysis was done by MS Excel 07 and GraphPad InStat software. P $<0.05$ was considered significant.

\section{RESULTS}

In our study 101 patients (84.16\%) were male and 19 (15.84\%) were female (Figure 1). The male-to-female ratio was 5.3: 1 . Out of 120 patients, 35 (29.16\%) patients had uncomplicated falciparum malaria and 85 patients (70.83\%) had presented with complicated falciparum malaria. Maximum number of patients $50(41.6 \%)$ were in age group of 21 - 30 years followed by $28(23.3 \%)$ in $13-20$ and 31 - 40 age group (Figure 2).

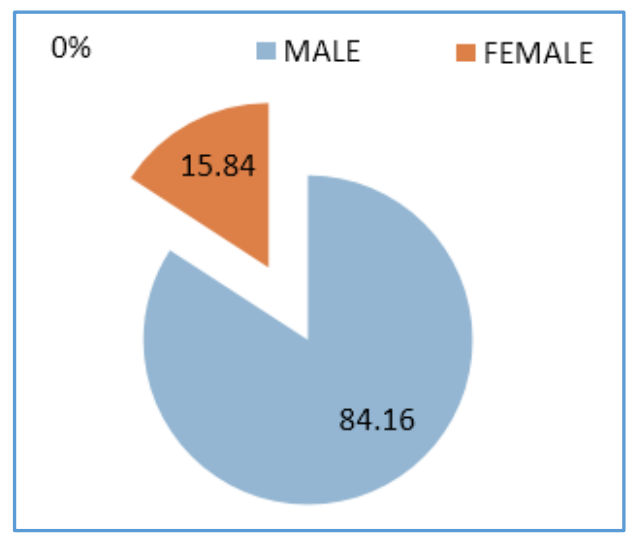

Figure 1. Sex Distribution
Fever was present in $100 \%$ of cases. 59 patients (49.16\%) had headache and altered sensorium in 45 patients $(37.5 \%)$. 12 patients (10\%) presented with convulsions and loose motions. 25 patients $(20.8 \%)$ had respiratory distress and 25 patients $(20.8 \%)$ had decreased urine output. Bleeding manifestations was seen in 4 patients (3.30\%) (Table 1$)$.

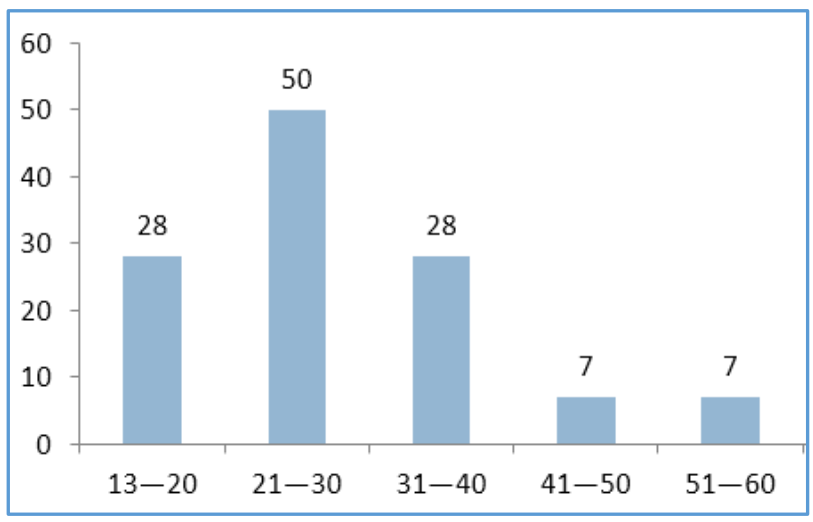

Figure 2. Age Distribution of Patients

\begin{tabular}{|c|c|c|}
\hline Symptoms & Number of Cases & Percentage (\%) \\
\hline Fever & 120 & 100 \\
\hline Chill and Rigor & 115 & 95.80 \\
\hline Nausea and Vomiting & 62 & 51.60 \\
\hline Headache & 59 & 49.16 \\
\hline Altered Sensorium & 45 & 37.50 \\
\hline Convulsion & 12 & 10 \\
\hline Loose Motion & 12 & 10 \\
\hline Respiratory Distress & 25 & 20.80 \\
\hline $\begin{array}{c}\text { Oliguria } \\
\text { (<400 mL in 24 hrs.) }\end{array}$ & 25 & 20.80 \\
\hline Bleeding Manifestation & 4 & 3.30 \\
\hline Table 1. Clinical Symptoms of Patients admitted in \\
Hospital
\end{tabular}

\begin{tabular}{|c|c|c|}
\hline Physical Sign & Number of Cases & Percentage (\%) \\
\hline Pallor & 57 & 47.50 \\
\hline Icterus & 52 & 43.33 \\
\hline Dehydration & 28 & 23.30 \\
\hline Hypotension & 17 & 14.16 \\
\hline Oedema & 19 & 15.83 \\
\hline Hepatomegaly & 52 & 43.33 \\
\hline Splenomegaly & 81 & 67.50 \\
\hline Basal Crepitation & 16 & 13.33 \\
\hline Acidotic Breathing & 25 & 20.83 \\
\hline \multicolumn{2}{|c|}{ Table 2. Physical Sign } \\
\hline \multicolumn{2}{|c|}{} \\
\hline
\end{tabular}

In our study 57 (47.5\%) subjects had pallor, 52 (43.33\%) had icterus, 17 (14.16\%) had systolic blood pressure $<100$ $\mathrm{mmHg}$, hepatomegaly was observed in 52 (43.33\%), splenomegaly was present in $81(67.5 \%)$. Respiratory sign (crackle) was observed in 16 (13.33\%), while 25 (20.8\%) subjects had acidotic breathing (Table 2).

Out of 120 subjects, 85 (70.83\%) patients suffered from severe falciparum malaria (Table 3). 43(35.83\%) patients had cerebral malaria. Jaundice was present in $52(43.33 \%)$ patients and $41(34.16 \%)$ patients had acute kidney injury (Table 4). 8 (6.67\%) patients had severe anaemia $(\mathrm{Hb}<5$ $\mathrm{gm} / \mathrm{dL})$. 


\begin{tabular}{|c|c|c|}
\hline Manifestations & Number of Cases & Percentage (\%) \\
\hline $\begin{array}{c}\text { Jaundice } \\
\text { (S. bilirubin }>3 \mathrm{mg} / \mathrm{dL})\end{array}$ & 52 & 43.33 \\
\hline Cerebral Malaria & 43 & 35.83 \\
\hline Acute Kidney Injury & 41 & 34.16 \\
\hline Pulmonary Oedema & 16 & 13.3 \\
\hline Bleeding Manifestation & 4 & 3.33 \\
\hline $\begin{array}{c}\text { Severe Anaemia } \\
(\mathrm{Hb}<5 \mathrm{gm} \%)\end{array}$ & 8 & 6.67 \\
\hline Hypoglycaemia & 4 & 3.33 \\
\hline \multicolumn{3}{|c|}{ Table 3. No. of Cases of Severe Falciparum Malaria } \\
\hline
\end{tabular}

Pattern of renal involvement showed that $33.33 \%$ had albuminuria. The serum creatinine was in the range of 1.5-18 $\mathrm{mg} / \mathrm{dL}$ and blood urea was $88-445 \mathrm{mg} / \mathrm{dL}$. Among the AKI patients, $20.83 \%$ had oliguric and $13.33 \%$ had non-oliguric renal failure (Figure 3). Most of the patients were in AKIN stage 3 (46.4\%). Renal replacement therapy was required in 25 (60.9\%) cases (Figure 4).

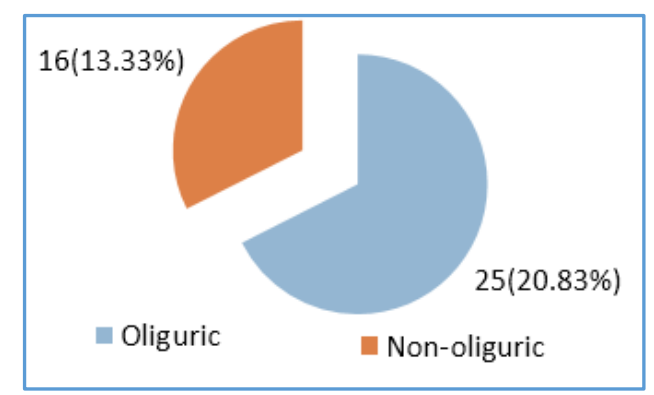

Figure 3. Distribution of Oliguric and Non-Oliguric Kidney Injury

\begin{tabular}{|c|c|c|}
\hline Category & Number of Cases & Percentage (\%) \\
\hline No Kidney Injury & 79 & 65.84 \\
\hline Acute Kidney Injury & 41 & 34.16 \\
\hline Total & 120 & 100.00 \\
\hline \multicolumn{2}{|c|}{ Table 4. Incidence of Acute Kidney Injury in the } \\
Study Subjects
\end{tabular}

\begin{tabular}{|c|c|c|}
\hline Stage & Number of Cases & Percentage (\%) \\
\hline 1 & 11 & 26.8 \\
\hline 2 & 11 & 26.8 \\
3 & 19 & 46.4 \\
\hline Total & $\mathbf{4 1}$ & $\mathbf{1 0 0 . 0 0}$ \\
\hline \multicolumn{2}{|c|}{ Table 5. AKIN Stage of Patients } \\
\hline
\end{tabular}

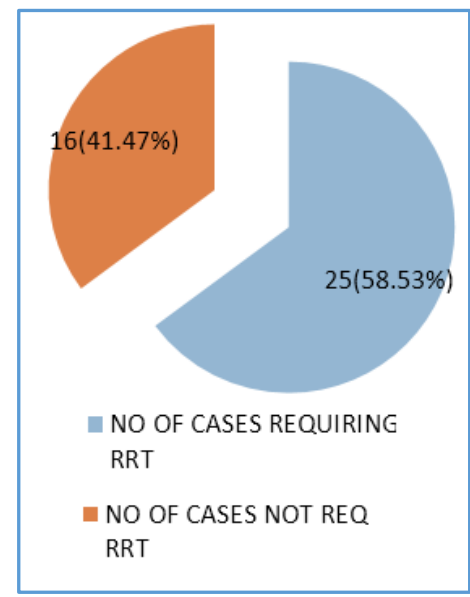

Figure 4. Requirement of Renal Replacement Therapy
Overall, mortality among 120 cases of falciparum malaria was $13.33 \%$ (16 patients). Mortality due to malarial AKI was $24.39 \%$, though it was not statistically significant ( $p>0.05$ ).

\section{DISCUSSION}

In this study, males were the most affected 101 patients $(84.16 \%)$ and females only 19 (15.84\%). The male-to-female ratio was 5.3: 1 .

Most of the patients were in the age group of $21-30 \mathrm{yrs}$. followed by $28(23.3 \%)$ in $13-20$ and $31-40$ age group. Remaining 7 (5.8\%) were found in the age group of 41 - 50 and $51-60$. Mean age of the patients were $29.03 \pm 10.71$ SD.

Fever was the most common symptom. Jaundice was observed in $52(43.33 \%)$ patients. Two studies also reported similar findings.7,8 Jaundice in falciparum malaria is due to intravascular haemolysis of parasitized RBCs, hepatic dysfunction and microangiopathic haemolysis due to DIC. ${ }^{9}$

Cerebral malaria was detected in 43 patients (35.83\%). Three studies from India also reported similar findings. 10,11,12 Anaemia was observed in 57 (47.5\%) patients in our study, out of which severe anaemia was present in 8 (6.67\%) cases. Two studies also reported similar incidence of severe anaemia. ${ }^{13,14}$

The incidence of complicated falciparum malaria was $70.83 \%$ (85 cases). Our incidence was higher than three other studies. $8,11,15$ This is because falciparum malaria is endemic in North East India.

Incidence of AKI was $34.16 \%$ (41 patients) in our study. Mahakur AC and Mohanty S also reported similar findings in their study. ${ }^{16,17}$ However Sitprija V, Murthy G and Gupta BK reported lower incidence of AKI in their study.10,12,18 Krishnan reported higher incidence of AKI (89\%) in his study. ${ }^{1}$

Oliguric kidney injury was more common $(20.83 \%)$ than non-oliguric injury in our study (13.33\%). Gupta BK et al (2012) and Mohapatra MK et al (2012) reported 24.3\% and $20.8 \%$ cases of oliguria in their study patients. However, higher incidence was reported by Mannan JA et al (2006), who found $76.09 \%$ of oliguric malarial kidney injury and Shukla VS et al (2013) observed 44.6\%.

25 patients (60.9\%) out of 41 malarial AKI needed haemodialysis, while 16 patients did not require dialysis. 16 patients expired out of 120 cases of falciparum malaria taking the mortality rate to $13.33 \%$ in our study. 10 patients out of 41 malarial AKI died. So, mortality due to malarial AKI in our study was $24.39 \%$.

In our study mortality due to malarial AKI (24.39\%) was higher than overall mortality (13.33\%), which was not statistically significant. Shukla VS also reported that severity of renal dysfunction was not associated with mortality risks. ${ }^{19}$ The mortality was higher in patients in AKIN stage 3 (36.84\%) than in stage 2 and 3 (18.18\% and 9.09\%) respectively.

\section{CONCLUSION}

In the present study, most patients presented with fever and majority had severe malaria. Among the complicated cases, most of the patients had malarial acute kidney injury and required haemodialysis. Majority of the malarial AKI patients presented with oliguria and albuminuria. Mortality was higher in patients with acute kidney injury, and was even more in haemodialysed patients, though it was not statistically significant. 


\section{REFERENCES}

[1] Krishnan A, Karnad DR. Severe falciparum malaria: an important cause of multiple organ failure in Indian intensive care unit patients. Crit Care Med 2003;31(9):2278-84.

[2] Mishra SK, Das BS. Malaria and acute kidney injury. Semin Nephrol 2008;28(4):395-408.

[3] Kanodia KV, Shah PR, Vanikar AV, et al. Malaria induced acute renal failure: a single center experience. Saudi J Kidney Dis Transpl 2010;21(6):1088-91.

[4] National Vector Borne Disease Control Program, Malaria Situation in India. Annual Report 2014-15.

[5] World Health Organisation. Guidelines for treatment of malaria. $2^{\text {nd }}$ edn. Geneva: World Health Organization 2010.

[6] Mehta RL, Kellum JA, Shah SV, et al. Acute kidney injury network: report of an initiative to improve outcomes in acute kidney injury. Crit Care 2007;11(2):R31.

[7] Ali H, Ahsan T, Mahmood T, et al. Parasite density and the spectrum of clinical illness in falciparum malaria. J Coll Physicians Surg Pak 2008;18(6):362-8.

[8] Malhotra Y, Pant BP, Khare RL, et al. Study of severity assessment and risk stratification of falciparum malaria in terms of hospital mortality in adults. Journal of Evolution of Medical and Dental Sciences 2015;4(61):10648-56.

[9] Srivastava A, Khanduri A, Lakhtakia S, et al. Falciparum malaria with acute liver failure. Trop Gastroenterol 1996;17(3):172-4.

[10] Murthy GL, Sahay RK, Srinivasan VR, et al. Clinical profile of falciparum malaria in a tertiary care hospital. J Indian Med Assoc 2000;98(4):160-2.
[11] Mohapatra MK, Dash LK, Barih PK, et al. Profile of mixed species (Plasmodium vivax and falciparum) malaria in adults. J Assoc Physicians India 2012;60:204.

[12] Gupta BK, Nayak KC, Kumar S, et al. Oliguric and nonoliguric acute renal failure in malaria in west zone of Rajasthan, India-A comparative study. Journal of Acute Disease 2012;1(2):100-6.

[13] Kochar D, Kochar SK, Agrawal RP, et al. The changing spectrum of severe falciparum malaria: a clinical study from Bikaner (northwest India). J Vector Borne Dis 2006;43(3):104-8.

[14] Mohapatra MK. The natural history of complicated falciparum malaria--a prospective study. J Assoc Physicians India 2006;54:848-53.

[15] Wasnik PN, Manohar TP, Humaney NR, et al. Study of clinical profile of falciparum malaria in a tertiary referral centre in Central India. J Assoc Physicians India 2012;60:33-6.

[16] Mahakur A, Panda SN, Nanda BK, et al. Malarial acute renal failure. $\mathrm{J}$ Assoc Physicians India 1983;31(10):633-6.

[17] Mohanty S, Mishra SK, Pati SS, et al. Complications and mortality patterns due to plasmodium falciparum malaria in hospitalized adults and children, Rourkela, Orissa, India. Transactions of the Royal Society of Tropical Medicine and Hygiene 2003;97(1):69-70.

[18] Sitprija V, Vongsthongsri M, Poshyachinda V, et al. Renal failure in malaria: a pathophysiologic study. Nephron 1977;18(5):277-87.

[19] Shukla VS, Singh RG, Rathore SS. Outcome of malariaassociated acute kidney injury: a prospective study from a single center. Ren Fail 2013;35(6):801-5. 